\title{
PRODUCCIÓN Y COMERCIALIZACIÓN DEL TINTE EN UGARIT
}

\author{
Juan Álvarez García \\ (Centro Superior de Estudios de Oriente Próximo y Egipto, Universidad Autónoma de Madrid)
}

\begin{abstract}
RESUMEN
La cuestión del tinte en la antigüedad ha atraído a lo largo de la historiografia un gran interés por parte de los especialistas. Para esta línea de investigación, Ugarit ofrece grandes posibilidades de estudio tanto textual como arqueológico. Así pues, los tintes que aparecen con más frecuencia en las fuentes son el azul, la púrpura, el rojo y el verde, cada uno con una serie de materiales y procesos especificos necesarios para ser fabricados. Igualmente, se han identificado varias estructuras con posibles talleres donde se llevaría a cabo la manufactura del tinte. Por otro lado, las fuentes también nos hablan de la fama internacional que adquirieron estos tejidos, siendo altamente cotizados en cortes extranjeras y distribuidos a través de redes diplomáticas y comerciales.
\end{abstract}

\section{PALABRAS CLAVE}

Tintura, tejidos, taller, tributo, regalo, comercio.

\section{ABSTRACT}

The topic of dyes in the antiquity has attracted a great interest by specialists along the historiography. For this line of research, Ugarit offers great study possibilities, from the textual as well as from the archaeological point of view. So then, dyes that appear more frequently in sources are blue, purple, red and green, each one with a set of specific materials and processes necessaries for being produced. Likewise, some structures have been identified with workshops where the manufacture of dyes was carried out. Furthermore, sources also talk about the international fame that these textiles achieved, because they were highly valued in foreign royal courts and distributed in diplomatic and commercial networks.

\section{KEYWORDS}

Dye, textiles, workshop, tribute, present, trade.

\section{Introducción}

De entre los productos comercializados en la Antigüedad, posiblemente el comercio de telas tintadas sea uno de los que más atracción ha generado en la historiografía sobre el Próximo Oriente. Tal vez los tintes nos evoquen una vez más ese mágico y exótico oriente, aquel brillante mundo donde los destellos de luces y colores impregnan imágenes y descripciones como los que se pueden percibir en los paisajes remotos de las Mil y una noches ${ }^{l}$. En este sentido, no podemos pasar por alto la expectación y admiración que generó y sigue generando en la historiografía colores como la púrpura, del que los autores clásicos ${ }^{2}$ y diferentes textos bíblicos atribuyen su invención a los fenicios. Así lo señala la magnífica elegía que el profeta Ezequiel hace a la caída de la ciudad de Tiro y en la que menciona sus valiosos tejidos teñidos ${ }^{3}$ :

“...Jarán, Kanné y Edén traficaban contigo; también traficaban contigo Aššur y Kilmad. Éstos traficaban contigo en vestidos de lujo, mantos de púrpura violeta y bordados, tapices de colores, maromas trenzadas y robustas: todo esto se encontraba en tu mercado..."

\footnotetext{
${ }^{1}$ Las primeras traducciones de Las mil y una noches destacaron y exageraron los aspectos más sensuales de lo que se denominó, en la literatura de viajes europea, "el oriente" (Brilli 2018: 24-25).

${ }^{2}$ Contamos, por ejemplo, con la descripción que hace Estrabón en su Geografia (XVI, 23) sobre los tintes púrpura fenicios.

${ }^{3}$ Ez 27, 23-24.
}

Isimu 23 (2020): 21-39

https://doi.org/10.15366/isimu2020.23.001

ISSN: 1575-3492 
No obstante, ni se trató de una moda que implantaron los fenicios ni fue un comercio exclusivo y particular del I milenio a.C. sino que ya se había desarrollado un interés por parte de las élites políticas y económicas del Próximo Oriente durante el periodo inmediatamente anterior, el Bronce Final. Durante esta etapa surgieron gustos compartidos por parte de las mencionadas élites, entre los cuales se cuenta el consumo de tejidos teñidos ${ }^{4}$.

Así pues, a título de hipótesis, podemos trazar una línea continua en lo que respecta a la producción y comercialización de tinte durante el I milenio a.C. y el Bronce Final: que los principales centros productores y distribuidores se encontraban en la costa del Levante Mediterráneo y que, tanto en una época como en la otra, las actividades comerciales, en general, y el lucrativo intercambio de estas selectas telas, en particular, atrajeron la atención de los grandes actores políticos de la época.

Si bien en la época del I milenio a.C., fueron grandes imperios hegemónicos como el Asirio $^{5}$ o el Persa ${ }^{6}$ los que se interesaron por la riqueza acumulada en las ciudades fenicias del Levante, en el Bronce Final, la coexistencia equilibrada entre grandes potencias territoriales como Egipto, Mitanni, Hatti, Asiria o Babilonia ${ }^{7}$ ofrecía una multiplicidad mayor de agentes involucrados en el comercio; agentes que, debido a ese relativo equilibrio político, entraron en un estadio de cierta interdependencia ${ }^{8}$ y se vieron obligados a encontrar en aquellas ciudades del Levante mediterráneo los espacios donde poder llevar a cabo los intercambios.

De entre los principales productores y distribuidores de tejidos teñidos del Bronce Final, por no decir el principal, está la ciudad y reino de Ugarit, cuyos textos y restos arqueológicos encontrados tanto en palacios como en casas particulares nos hablan de una pujanza económica y de unas intensas relaciones comerciales. Particularmente, la importancia de la producción y el comercio de tejidos tintados en esta ciudad ya fue advertida por C. F. A. Schaeffer quien estableció esta industria como un elemento importante de la economía ugarítica en su artículo "Une industrie d'Ougarit: la pourpre" ( $A A S$, 1951). Sin embargo, una de las mayores contribuciones al estudio de los tintes en Ugarit fue llevada a cabo por W. H. Van Soldt en su artículo "Fabrics and dyes in Ugarit" $(U F, 1990)$ en donde planteaba los distintos tipos de tintes analizando los términos utilizados tanto en textos silábicos como alfabéticos. En este artículo también propone distintas fuentes, tanto animales como vegetales y minerales, para la extracción de los colores. Finalmente, otras importantes contribuciones fueron las realizadas por V. Matoïan y J. P. Vita en las publicaciones "Les textiles à Ougarit. Perspectives de la Recherche" (UF, 2009) y "Wool Production and Economy at Ugarit" (Oxford, 2014), en ambos artículos analizan el proceso de producción de los textiles en Ugarit, dentro del cual señalan el procedimiento y materiales para su teñido.

No obstante, una de las mayores dificultades a las que nos enfrentamos en el estudio de los tintes en el Próximo Oriente antiguo, en general, y en Ugarit, en particular, es la práctica ausencia de textos que nos describan el proceso, así como muy pocas evidencias arqueológicas sobre las que poder trabajar y alcanzar conclusiones determinantes, puesto que escasas veces los textiles, al tratarse de material orgánico, se conservan en el registro arqueológico ${ }^{9}$. Pese a que los textos hacen especial referencia a los tejidos teñidos de rojo, azul y púrpura, los cuales debieron generar auténtico furor en los mercados internacionales de

\footnotetext{
${ }^{4}$ Van de Mieroop 2007: 164-166.

${ }^{5}$ Kiely 2019: 85.

${ }^{6}$ Kiely 2019: 88.

${ }^{7}$ Cohen 1992: 248-249.

${ }^{8}$ Zaccagnini 2000: 141.

${ }^{9}$ Únicamente se conservan evidencias arqueológicas de material orgánico en condiciones de extrema sequedad o de práctica ausencia de oxígeno (Sukenik et al. 2017: 2).
} 
la época ${ }^{10}$, no se pueden establecer correspondencias netas entre las referencias a pigmentos en los textos y la gama de colores actual, puesto que se pueden dar casos en que los términos antiguos reconozcan matices de brillo, intensidad o, incluso, mezcla. Pese a todo, gracias a la aportación de las Ciencias Naturales como la Química, la Botánica y la Zoología, se han conseguido grandes avances en el conocimiento del proceso de tintado; además, estudios sobre restos arqueológicos como el vidrio coloreado aportan una gran cantidad de información sobre el origen de los posibles pigmentos utilizados.

Así pues, el objetivo de este artículo es el estudio del proceso productivo que implicaba el teñido de tejidos en Ugarit y su distribución en circuitos comerciales y diplomáticos internacionales. De tal manera que, en un primer momento, se analizarán los distintos tipos de tintes que son mencionados en los textos, la importación o extracción de la materia prima para fabricarlos, así como del posible proceso manufacturero necesario para poder extraer el color y fijarlo al tejido. Posteriormente, se estudiarán los textos que nos han permitido rastrear la distribución de estas telas en los mercados internacionales de la época de cara a, finalmente, identificar rutas y compradores preferentes.

\section{Los pigmentos: fuentes y producción}

De entre los diferentes tintes que aparecen en los textos epistolares y administrativos, destacan varios de ellos que se corresponderían, a grandes rasgos, con el azul, la púrpura, el rojo y el verde, aunque las listas lexicográficas mencionan también la lana negra y amarilla ${ }^{11}$.

\subsection{Azul lapislázuli}

En varios documentos encontrados en Ugarit se hace referencia a lana ${ }^{12}$ tintada de color "azul lapislázuli"13. Este color aparece bajo varios términos diferentes: uqnû en acadio e iqnu

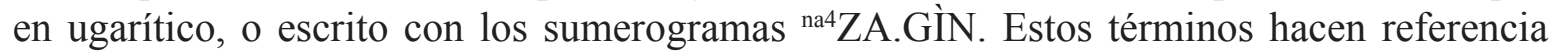
tanto al color azul intenso propio de esta piedra semipreciosa ${ }^{14}$ como a la piedra en sí $^{15}$. No obstante, textos en ugarítico procedentes de Ras Ibn Hani cuentan con listas de tejidos teñidos de este mismo tipo de azul, pero son traducidos por "púrpura azulada"16.

Pese a que no podemos determinar con total seguridad el origen del pigmento utilizado para las tinturas, sí se han hecho estudios químicos sobre restos y objetos de vidrio azul encontrado en varios yacimientos y todo indica a que la fuente principal de este color para muchas de las sociedades del Próximo Oriente fue el cobalto. En este sentido, objetos de vidrio azul encontrados en Ugarit cuentan con una composición química muy semejante al cobalto

\footnotetext{
${ }^{10}$ Thavapalan 2016: 166.

${ }^{11}$ Van Soldt 1990: 339.

${ }^{12}$ La materia prima fundamental que fue objeto de tintado fue la lana, puesto que, al tratarse de fibra animal, las proteínas que la componen son más susceptibles de absorber el color (Sukenik et al. 2017: 2), no como el lino, otro de los materiales que son objeto de manufactura en Ugarit, como se aprecia en los textos: RS [varia 26] (RSO VII: 66-67), RS 25.138 (Lackenbacher 2002: 296), RS 34.134 (RSO VII: 68-70) RS 34.167+175 (RSO VII: 57-61), RS 88.2158 (RSO XIV: 239-247), RS 94.2002+2003 (RSO XXIII: 81-86) y RS 94.2377 (RSO XXIII: 172-173).

${ }^{13}$ El lapislázuli fue posiblemente la piedra semipreciosa que mayor fama adquirió en Próximo Oriente, tanto por sus cualidades ornamentales destacando su color azul intenso, como por su rareza, siendo con toda probabilidad extraído de las montañas de Badakhshán, en Afganistán (del Cerro Linares 2009: 81). Es muy posible que esta fama del lapislázuli se extendiera a las prendas teñidas con un color similar y que, al llevarlas, aportaran prestigio y distinción a sus propietarios.

${ }^{14}$ CAD 20: 201-202.

${ }^{15}$ CAD 20: 195-201.

${ }^{16}$ RIH 83/42+83/43 (Bordreuil, Pardee, y Roche-Hawley 2019: 85-86). En este sentido, W. H. van Soldt (1990: 343-344) plantea que tal vez el término iqnu haga referencia a un tipo de púrpura oscura.
} 
que también se encuentra en los oasis de Dahla y Kharga en Egipto ${ }^{17}$, de donde se extraía un tipo de alumbre cobaltífero muy explotado durante el periodo del Bronce Final ${ }^{18}$. Este mineral se encuentra bien representado en documentos de Ugarit como aban gabê ${ }^{\mathrm{NA}_{4}} \mathrm{KA}$.BI en los textos acadios y abn șrp en los ugaríticos ${ }^{19}$. Pese a que, entre los documentos que describen relaciones comerciales con Egipto, no contamos con referencias a la importación de piedra de alumbre, sí contamos con varias referencias al uso y comercialización de este mineral en textos procedentes de casas privadas ${ }^{20}$, así como también en los archivos palaciales ${ }^{21}$ o en el palacio de Ras Ibn Hani ${ }^{22}$. También hay que decir que la mayoría de los documentos en los que se detallan los materiales intercambiados entre Egipto y Ugarit son todos documentos diplomáticos oficiales, por lo que podemos pensar que este mineral era importado a través de circuitos comerciales privados. Esta piedra de alumbre tenía además la función de servir de mordiente en las tinturas; sin embargo, para que pueda tener este efecto debía ser liberado de impurezas, pues raramente aparece en forma pura en la naturaleza ${ }^{23}$.

Así pues, se extraía de este alumbre cobaltífero el mordiente y el pigmento mediante una reacción química consistente en disolver la piedra de alumbre en agua y añadirle un alcaloide como el natrón, de esta manera se pueden separar los metales presentes en el mineral bruto, de entre ellos el cobalto, y posteriormente tras la desecación y recristalización de la solución, usar el alumbre como mordiente y el cobalto depositado en el fondo de la solución como colorante una vez calentado ${ }^{24}$. De hecho, la obtención de un pigmento azul a partir del calentado de cobalto ofrece una serie de ventajas puesto que no es necesario controlar la temperatura, las impurezas de otros metales o la atmósfera de cocción para obtener el color azul25.

Sin embargo, pese a que el uso del cobalto para extraer el pigmento azul haya sido demostrado en el vidrio, no contamos con restos que nos lleven a pensar que dichas sales de cobalto calentadas fueran utilizadas en la tintura de tejidos. En cambio, cabe otra traducción posible para el color $u q n \hat{u}$, que se trate del colorante extraído de la planta Isatis tinctoria así como de la Indigosfera tinctoria ${ }^{26}$, las cuales son nativas de la región y aparecen en textos cuneiformes mesopotámicos como "planta de lapislázuli" (šammi uqnâti) ${ }^{27}$. El uso de este tipo de plantas para la tintura está demostrado arqueológicamente en restos de fibras de lana halladas en Timna ${ }^{28}$. No obstante, el teñido con ellas requiere un proceso complejo puesto que no produce una sustancia soluble en el agua, sino que requiere de procesos químicos por los cuales la planta debe ser tratada previamente con aditivos en un proceso de reducción controlando la temperatura del agua (entre $30^{\circ}$ y $40^{\circ}$ ) y luego, una vez teñida la prenda, ésta debía someterse a nuevos procesos de secado y oxidación para conseguir alcanzar el color final y que éste fuera permanente ${ }^{29}$. Además, contamos con la tablilla WA $62788+82978$,

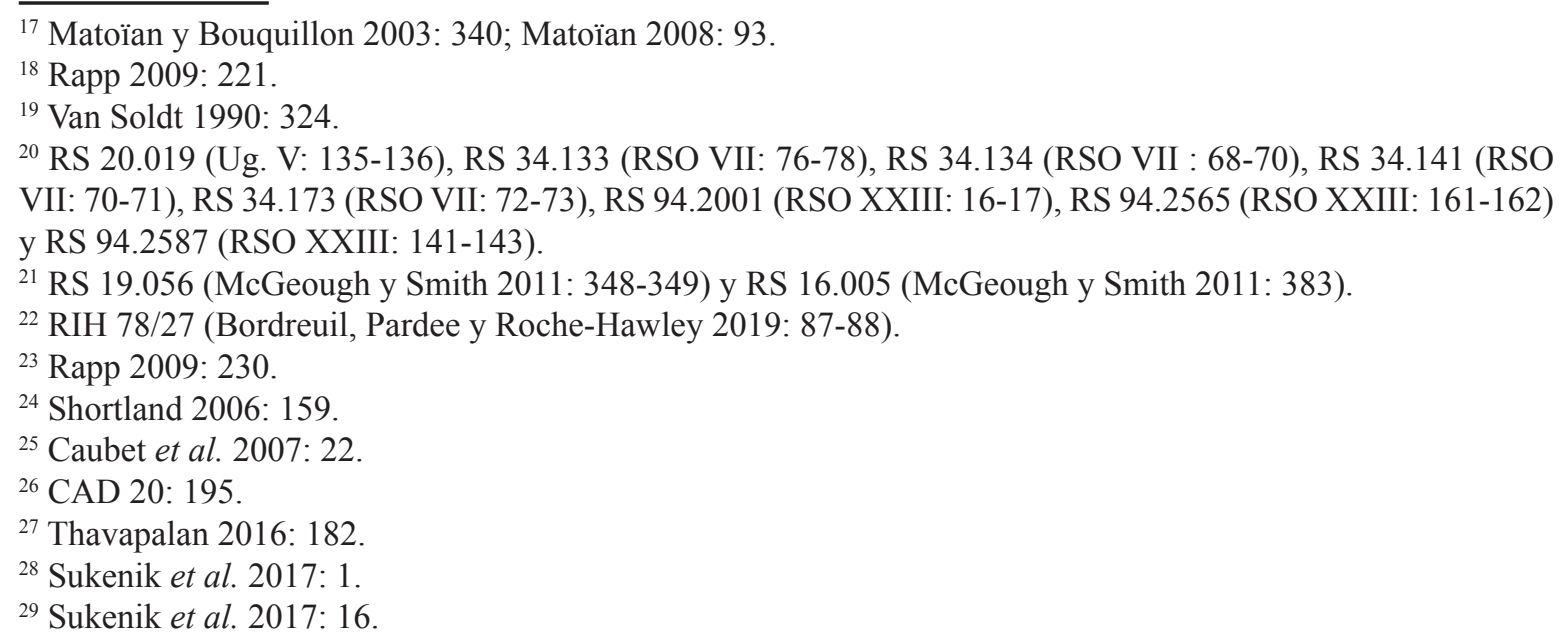


datada en el s. VII a.C., en la que se detallan los procesos para conseguir diferentes matices que van desde el verde azulado al púrpura intenso por los cuales el tono final se obtendría a través del calibrado de los diferentes aditivos así como del número de baños de tinte dados a la prenda ${ }^{30}$.

\subsection{Púrpura}

Los textos, tanto procedentes de Ugarit como de otros archivos contemporáneos, recogen varios tipos de púrpura, destacando la púrpura azul (takiltu) y la púrpura roja (argamannu). Ambos colores se originarían del uso de diferentes especies de múrices ${ }^{31}$; de la subespecie Hexaplex trunculus se extraería la denominada púrpura azul y de la subespecie Bolinus brandaris y Stramonita haemastoma la púrpura roja ${ }^{32}$. El uso del murex para la extracción de la púrpura esta atestiguado arqueológicamente en los restos de tejidos encontrados en las tumbas reales de Qața ${ }^{33}$. Sin embargo, los restos hallados aquí recogen una gama de colores mucho más amplia ${ }^{34}$.

En Ugarit, la especie que se ha encontrado en mayor cantidad es la denominada Hexaplex trunculus $^{35}$, coincidiendo con la amplia representación de la lana takiltu en los textos de esta ciudad $^{36}$. El conjunto de conchas de este molusco encontrado en la bahía de Minet el Behida $^{37}$, junto a los restos de un recipiente cerámico que contenía tinte púrpura, además de otros restos de conchas de murex encontrados en la capital y en el palacio de Ras Ibn Hani ${ }^{38}$ demuestran la utilización de esta especie animal para la extracción del pigmento púrpura. Por su parte, la casa situada al sur del denominado templo de los ritones ${ }^{39}$, la denominada Casa de la Muralla ${ }^{40}$ y en algunas de las estancias del palacio norte de Ras Ibn Hani ${ }^{41}$ se hallaron restos de conchas murex formando parte de los suelos, los cuales pudieron utilizarse para reforzar dichas superficies y provendrían de los restos de la explotación de la industria de la púrpura $^{42}$. Por su parte, la extracción del tinte requería un proceso consistente en la extracción de la glándula con la que el molusco genera la sustancia púrpura, su triturado y posterior cocción en agua durante diez o quince días a una temperatura moderada ${ }^{43}$.

\footnotetext{
${ }^{30}$ Finkel, Granger-Taylor y Cardon 1999: 64-65.

31 Familia de gasterópodos marinos carnívoros depredadores que habitan zonas de litoral como bahías, ensenadas, rías, etc. con aguas calmadas y fangosas ricas en detritos y materia orgánica de la que se alimentan (Fernández Uriel 2010: 70)

32 Thavapalan 2016: 116-117.

${ }^{33}$ James et al. 2009: 1112.

${ }^{34}$ Thavapalan 2016: 116.

${ }^{35}$ Matoïan y Vita 2014: 323.

${ }^{36}$ Van Soldt 1990: 329-331. Sin embargo, S. Thavapalan (2016: 186) tiene serias dudas en torno a la relación directa entre la terminología de la púrpura en los textos y el pigmento extraído del murex, puesto que no contamos en los textos con referencias directas al proceso, por lo que considera la posibilidad de que la mayor parte de este tipo de tinte se extrajera a base de sucedáneos procedentes de plantas como la que hemos mencionado previamente, la Isatis tinctoria o la Indigosfera tinctoria. También argumenta el bajo precio del talento de lana teñido de púrpura (entre cuatro y cinco siclos de plata), en comparación con los costes de producción que tendrían las telas teñidas con murex.

${ }^{37}$ Matoïan y Vita 2009: 286.

${ }^{38}$ Matoïan y Vita 2014: 322. Los textos de Ras Ibn Hani también se hacen eco de esta producción de tejidos teñidos como el texto RIH 83/42+83/43 (Bordreuil, Pardee y Roche-Hawley 2019: 85-86).

${ }^{39}$ Mallet y Matoïan 2001: 95.

${ }^{40}$ Matoïan et al. 2013: 442-447.

${ }^{41}$ Bounni, Lagarce y Lagarce, 1998: 20.

${ }^{42}$ Matoïan y Vita 2014: 322-323.

${ }^{43}$ Fernández Uriel 2010: 124-126.
} 


\subsection{Rojo}

En cuanto a la lana roja (tabarru; šmt en ugarítico) de la que hablan algunas fuentes, no sabemos hasta qué punto los ugaritas ya utilizaban la cochinilla del roble (hurhuratu) para sacar el tinte rojo ${ }^{44}$. En ausencia de este insecto, la raíz de la planta Rubia tinctorum, nativa de la región del Próximo Oriente y de la cuenca mediterránea ${ }^{45}$, pudo usarse en Ugarit para conseguir el pigmento ${ }^{46}$. Una vez obtenido, el proceso de tintado es relativamente sencillo puesto que únicamente es necesario diluir los componentes en una solución con el mordiente para conseguir el teñido final ${ }^{47}$. Otra opción que se baraja para la obtención del tinte rojo está en el uso de la granada cuya combinación con el uso de la raíz de la Rubia tinctorum daría como resultado un color rojo anaranjado ${ }^{48}$. Por su parte, otra planta que también pudo utilizarse para obtener un tono rojo-violeta es la Alkanna tinctoria ${ }^{49}$.

\subsection{Verde}

En cuanto al tinte verde (hașerti), bien se pudo utilizar óxido de cobre ${ }^{50}$. Sin embargo, es posible que se requiriera una mezcla de componentes químicos para poder generar este pigmento. Por un lado, los egipcios ya descubrieron que se podía generar color verde mediante la mezcla de cobre y antimoniato de plomo (resultante de la calcinación de óxido de plomo con antimonio $)^{51}$; a través de este proceso se obtendría un tono verdigris o turquesa ${ }^{52}$. Por otro lado, pese a que no tenemos referencias a este proceso de obtención del pigmento en Ugarit, sí se han detectado cantidades de litargirio, un óxido de plomo de color amarillo o naranja, procedente del copelado del plomo argentífero que los ugaritas importaban de la región del Egeo $^{53}$.

No obstante, existe la posibilidad de que hubiera otra forma de obtener este color, que sería a través de la mezcla del tinte azul procedente de la Isatis tinctoria con el amarillo extraído de la granada ${ }^{54}$. Así pues, tendríamos como resultado un verde azulado que haría referencia al denominado color h̆ašmanu ${ }^{55}$ ( $p h n$ en ugarítico) que encontramos en algunos textos $^{56}$. Finalmente contaríamos con otro tipo de verde amarillento que en los textos aparece como handalatu ${ }^{57}$ (hndlt en ugarítico), cuyo proceso nos es desconocido.

\section{Los talleres y el proceso de teñido del textil}

Pese a la abundante información sobre la industria tintorera en Ugarit, apenas contamos con documentos que nos permitan describir el proceso, la organización del trabajo o los talleres en donde se llevaba a cabo ${ }^{58}$ más allá de las hipótesis que podemos plantear de acuerdo a los procesos químicos necesarios para la obtención de los diferentes colores.

\footnotetext{
${ }^{44}$ Van Soldt 1990: 346-347.

${ }^{45}$ Sukenik et al. 2017: 16.

${ }^{46}$ Van Soldt 1990: 347-348.

${ }^{47}$ Sukenik et al. 2017: 16.

${ }^{48}$ Thavapalan 2016: 181.

49 Thavapalan 2016: 182.

${ }^{50}$ Van Soldt 1990: 349.

${ }^{51}$ Caubet et al. 2007: 20.

52 Thavapalan 2019: 184.

${ }^{53}$ Dardallion 2012: 233.

${ }^{54}$ Thavapalan 2016: 185.

${ }^{55}$ Finkel, Granger-Taylor y Cardon 1999: 65. Por su parte, V. Matoïan y J. P. Vita (2014: 321) consideran que este término hace referencia a un color rojo púrpura semejante al color argamannu.

${ }^{56}$ RS 20.019 (Ug. V: 135-136), RS 34.180,4 (RSO VII: 127-128).

${ }^{57}$ Matoïan y Vita 2014: 321.

${ }^{58}$ Matoïan y Vita 2009: 486.
} 
Es muy probable que los talleres tintoreros se encontraran en zonas costeras con acceso directo a la materia prima y a los distintos productos necesarios para la industria del tinte que procedían del comercio internacional ${ }^{59}$. No obstante, se han identificado diferentes instalaciones, tanto en el centro urbano como en zonas portuarias, que $\mathrm{O}$. Callot ${ }^{60}$ relaciona con la industria del tinte. Concretamente se trata de instalaciones localizadas en la Casa $\mathrm{B}$ del $\hat{\text { llot }} \mathrm{VI}^{61}$ de la zona sur de la ciudad, otra en la Casa F del centro de la ciudad ${ }^{62}$ (fig. 1) y otras dos en el puerto de Minet el Behida ${ }^{63}$. En este último, destaca el espacio dentro de un gran edificio cercano al puerto, donde los restos de un recipiente cerámico que contenía tinte púrpura indicarían el lugar de producción ${ }^{64}$. Las instalaciones consisten en una cubeta circular o cuadrada de poca profundidad (en torno a los $50 \mathrm{~cm}$ ), una losa tallada plana cercana y una vasija parcialmente enterrada (fig. 2). Sin embargo, V. Matoïan y J. P. Vita ${ }^{65}$ discrepan en torno a la idea de que talleres del tinte se encontraran dentro de la ciudad, habida cuenta de que se trataba de actividades altamente contaminantes. Además, recientes estudios en los lugares señalados por O. Callot no han revelado ningún tipo de restos que señalen una actividad tintorera y señalan la posibilidad que se trate de simplemente un lugar lavado de lana ${ }^{66}$.

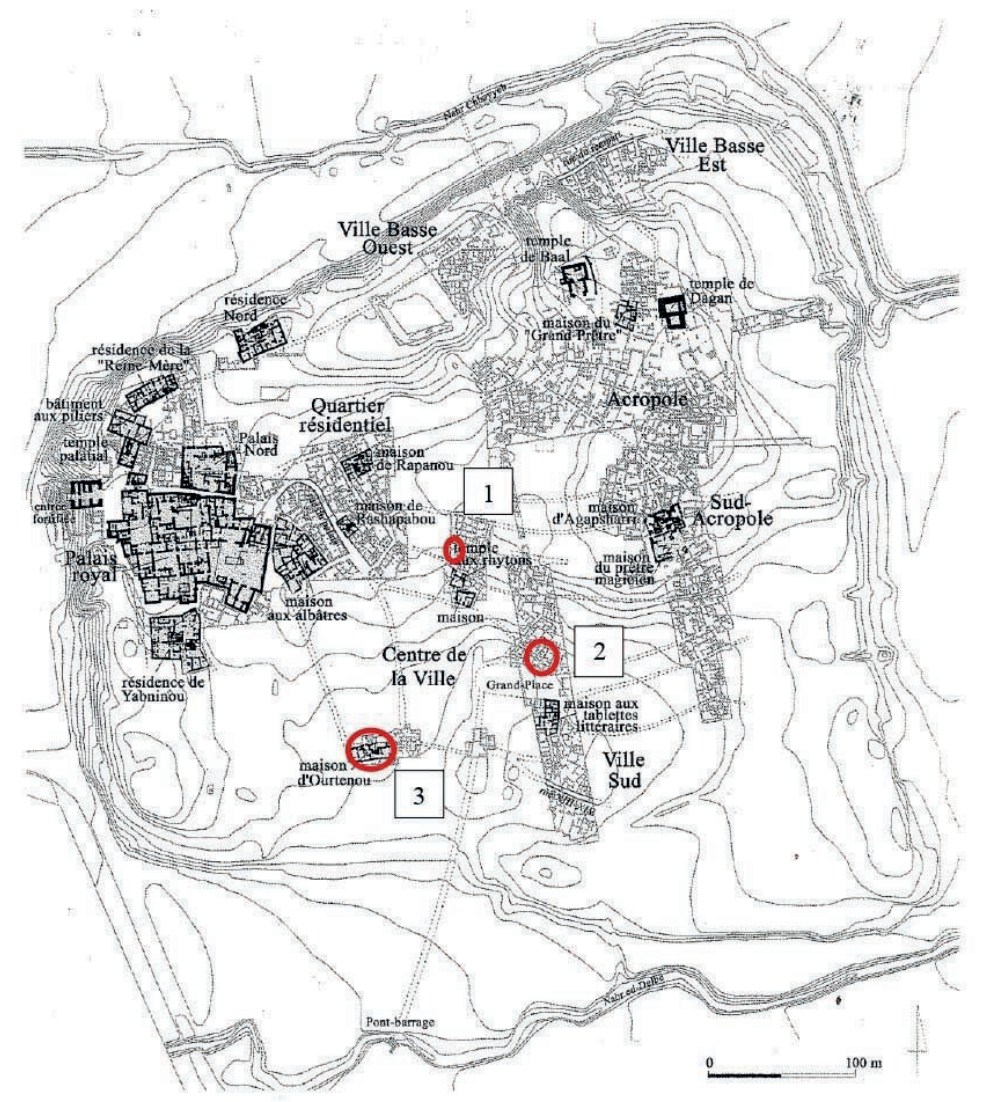

Fig. 1. Plano del yacimiento de Ras-Shamra-Ugarit (Galliano y Calvet 2004: 29) con los posibles talleres tintoreros en la denominada Casa F del centro de la ciudad (1), la Casa B del îlot VI (2) y, por otro lado, la que debió ser la sede de la denominada firme comercial, la Casa de Urtenu (3).

\footnotetext{
${ }^{59}$ Matoïan y Vita 2009: 286. En este sentido, no hay que olvidar que Ugarit contaría con un total de ocho puertos en su costa, los cuales también pudieron constituir centros manufactureros del tinte (Astour 1995: 58).

${ }^{60}$ Callot 1994: 190.

${ }^{61}$ Callot 1994: 33-37.

${ }^{62}$ Yon et al. 1983: 214, fig. 13; Yon, Lombard y Rensio 1987: 12; Callot 1994: 190.

${ }^{63}$ Schaeffer 1931: pl. XIV, fig. 1 y 4; Callot 1994: 190.

${ }^{64}$ Matoïan y Vita 2009: 286; Saadé 2011: 299; Matoïan y Vita 2014: 322.

${ }^{65}$ Matoïan y Vita 2009: 488.

${ }^{66}$ Matoïan y Vita 2014: 319-320.
} 
En cualquier caso, el proceso de teñido requería una serie de pasos. En primer lugar, para poder fijar el tinte a la lana, ésta debía ser previamente lavada a conciencia con el objetivo de eliminar cualquier impureza que pudiera impedir que se fijara el tinte a la fibra $^{67}$. Sin embargo, durante el lavado, la fibra de lana también perdía la lanolina, una grasa natural sin la cual es imposible que el pigmento se adhiera a la fibra, por lo que era necesario añadir en el proceso de teñido algún tipo de grasa que cumpliera dicha función, muy posiblemente aceite tal y como sugiere J. P. Vita ${ }^{68}$. Una vez preparado el tinte con el mordiente (en el caso de ser necesario) y que la lana ha sido convenientemente lavada, se vertería el tinte en la cubeta y dentro se dispondría el tejido que se teñiría mediante su pisado $^{69}$. Finalmente, una vez impregnada la lana del tinte, ésta se dispondría sobre la losa plana para su secado ${ }^{70}$.

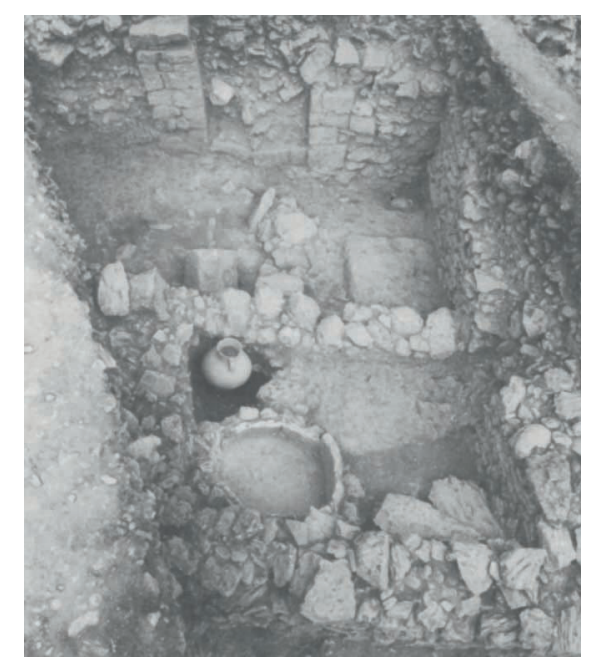

Fig. 2. Estructura interpretada como instalación tintorera aparecida en la Casa F del denominado Centro de la Ciudad (Yon et al. 1983, fig. 13).

\section{4.- Distribución y comercialización de los tejidos tintados}

\subsection{Los canales diplomáticos: tributos y regalos}

Diversos documentos del ámbito diplomático, como tratados y correspondencia entre altas esferas políticas internacionales, indican un gran interés por abastecerse de los tejidos ugaríticos. Posiblemente, uno de los más destacados sea el documento por el cual Suppiluliuma I de Hatti impuso tributo a Ugarit tras pasar bajo su tutela ${ }^{71}$. Entre los bienes que deben entregar, junto a los objetos en metales preciosos, destacan las grandes cantidades de lana tintada uqnû y de uqnû hašmani ${ }^{72}$.

No obstante, ciertos documentos procedentes de archivos encontrados en ámbitos privados amplían esta información, puesto que otras autoridades hititas también reclamarán su parte en términos de lana teñida, como es el caso del texto RS $20.216^{73}$ en donde el virrey de

\footnotetext{
${ }^{67}$ Vita 2017: 540.

${ }^{68}$ Vita 2017: 541.

${ }^{69}$ Fernández Uriel 2010: 147-148.

${ }^{70}$ Fernández Uriel 2010: 149.

${ }^{71}$ RS 17.227 (PRU IV: 40-44); Beckman 1996: 153-154.

${ }^{72}$ Este tributo será posteriormente reducido bajo el reinado de Mursili II mediante edicto real (Beckman 1996: 160-162) como compensación a la gran pérdida de territorio que sufrió el propio reino de Ugarit tras la rebelión del sucesor del rey Niqmaddu III, Arhalba.

${ }^{73} \mathrm{Ug}$. V: $108-110$.
} 
Karkemiš $^{74}$, al final de una serie de reproches relacionados con un matrimonio fracasado del rey de Ugarit, le reclama un cargamento de lana tintada. No siendo suficiente, encontramos igualmente documentos como RS $20.003^{75}$, RS $25.461^{76}$ y RS 94.237477, en los cuales diferentes autoridades y funcionarios de la corte hitita envían directamente a sus propios tintoreros $\left(s \bar{a} r i p \bar{u} t u^{78}\right)$ exigiendo, en numerosas ocasiones, "que no se les pongan impedimentos". Pero, en lo que respecta a esta hipotética obligación ugarita de abastecer de tinte a las autoridades hititas, sin lugar a dudas destaca la carta RS $94.5013^{79}$ en la que el rey de Hatti envía al rey de Ugarit un lote de lana que debe ser teñida acogiéndose a la figura jurídica del ilku, es decir, a los trabajos obligatorios que todo vasallo debía prestar a su señor ${ }^{80}$.

Al margen de los tributos, también encontramos que los tejidos tintados fueron un recurrente regalo en relaciones diplomáticas al poseer un alto contenido simbólico. Tal es el caso del texto RS $20.019^{81}$ en el que una princesa hitita intercambia regalos con la reina de Ugarit pidiéndole telas de lana tintadas de hašmanu, handalatu y dupašši (posiblemente amarillo ${ }^{82}$ ) o el documento RS $20.200 C^{83}$ en el que se menciona el envío de lana tintada a "un poderoso". Sin embargo, por encima de todos ellos se encuentra la carta RS 94.5026+502784. Se trata de una carta que escribe Ini-Teššub, rey de Karkemiš, a Šagarakti-Šuriaš, rey de Babilonia/Karduniaš, en relación a diferentes movimientos de población nómada en la frontera de Babilonia y al envío de regalos para su rey. La presencia de esta carta en Ugarit es problemática puesto que esta ciudad no se encuentra de ninguna manera en la ruta entre Karkemiš y Babilonia. Pese a ello, los regalos enviados consistentes en lana teñida de verde ${ }^{85}$ (hașerti) y aceites hacen pensar que muy posiblemente esta carta constituya en realidad una copia a modo de recibo que entregaría el mensajero para abastecerse de los cotizados regalos antes de emprender su marcha hacia Babilonia.

\subsection{Los circuitos comerciales. La firme}

Pese a que el papel de los objetos de lujo, como los tejidos tintados, en el intercambio de regalos y la entrega de tributos ha recibido mucho más tratamiento en la literatura científica ${ }^{86}$ debido a su vistosidad en las fuentes textuales, no se trata sino de la punta del iceberg de toda una serie de intercambios comerciales a larga distancia.

\footnotetext{
${ }^{74}$ Una de las formas por las cuales Suppiluliuma I de Hatti quiso afianzar su control sobre Siria fue situar a miembros de su propia familia al frente de importantes reinos sirios, creando una serie de apanages que se conocen en la historiografía como virreinatos. Concretamente se crearon dos, uno en Alepo y otro en Karkemiš (Bryce 2001: 225).

${ }^{75} \mathrm{Ug} . \mathrm{V}:$ 91-94.

${ }^{76}$ Lackenbacher 2002: 97.

${ }^{77}$ RSO XXIII: 147-148.

${ }^{78}$ Vita 2010: 325.

${ }^{79}$ RSO XXIII: 24.

${ }^{80}$ Márquez Rowe 2002: 2.

${ }^{81} \mathrm{Ug}$. V: 135-136.

${ }^{82}$ Matoïan y Vita 2014: 321.

${ }^{83} \mathrm{Ug}$. V: 100.

${ }^{84}$ RSO XXIII: 78-79.

${ }^{85}$ El tinte verde debió ser un tipo de tejido cotizado por la realeza mesopotámica, puesto que también nos encontramos en época neoasiria la imagen del rey Aššurnasirpal II de Asiria ataviado con una túnica verde en un ladrillo vidriado de Nimrud (845-850 a.C.) (Leight 2019: 144).

${ }^{86}$ Aquí debemos destacar la aportación de la historiografía italiana con M. Liverani (2003) a la cabeza quien ya plantea los mecanismos complejos de reciprocidad y redistribución por los cuales se organizaban estos intercambios en un contexto diplomático. Igualmente, destacamos el estudio de C. Zaccagnini (1973; 1990) en torno al intercambio de regalos y la retórica apreciable en tratados y correspondencia diplomática.
} 
En la frontera entre las relaciones diplomáticas y el puro comercio, entendido como actividad económica con búsqueda de beneficio, se encuentra el conjunto de actividades económicas llevadas a cabo por el propio palacio real. Es innegable que, pese al gran desarrollo que tuvo el comercio privado en Ugarit, el palacio real siguió siendo el principal polo de actividad económica a la luz de los datos que confirman una mayor envergadura en términos de propiedades y recursos. En primer lugar, debemos destacar las listas de pastores ${ }^{87}$ que revelan el control por parte del palacio real de mayores cantidades de cabezas de ganado ovino, principalmente registrados en las regiones del este y del noreste del territorio que controlaba el reino de Ugarit, cercano al piedemonte y con mejores pastos ${ }^{88}$. Sin embargo, los documentos que más aparecen relacionados con la manufactura textil son los inventarios de tejidos y prendas $^{89}$. En relación a esto también contamos con otros textos palaciales consistentes en listas de productores de tejidos ${ }^{90}$. Más concretamente en lo tocante a la fabricación del tinte, contamos también con textos procedentes del palacio real que señalan su vinculación con esta industria ${ }^{91}$.

Sin embargo, pese a que sí se aprecia en algunos documentos que el palacio real llevó la iniciativa económica en la puesta en venta y comercialización de tejidos ${ }^{92}$, dicha iniciativa no es comparable a la que debieron tener los comerciantes particulares ${ }^{93}$, hasta tal punto que se aprecia en numerosos documentos cómo el palacio real entrega a dichos mercaderes el producto para que lo saquen al mercado o lo distribuyan de diferentes maneras ${ }^{94}$. Mediante este sistema el palacio se aseguraba el papel principal en la regulación del comercio internacional sin necesidad de intervenir directamente en él ${ }^{95}$.

\footnotetext{
${ }^{87}$ RS 18.087 (McGeough y Smith 2011: 261-262) y RS 18.082 (McGeough y Smith 2011; 257-258).

${ }^{88}$ Matoïan y Vita 2014: 315-316.

${ }^{89}$ Concretamente, los textos RS 10.035 (McGeough y Smith 2011: 433-434), RS 15.003 (McGeough y Smith 2011: 97) y RS 19.062 (McGeough y Smith 2011: 351-352) recogen listas de distribución de lana en bruto, pero textos como RS 15.004 (McGeough y Smith 2011: 98-99), RS 15.032 (McGeough y Smith 2011: 107108), RS 15.034 (McGeough y Smith 2011: 107-108), RS 15.045 (McGeough y Smith 2011: 114), RS 15.076 (McGeough y Smith 2011: 133-134), RS 15.078 (McGeough y Smith 2011: 382-383), RS 15.169 (McGeough y Smith 2011: 137-138), RS 15.176bis (McGeough y Smith 2011: 88), RS 16.004 (McGeough y Smith 2011: 164-165), RS 17.111 (McGeough y Smith 2011: 212-213), RS 18.133 (McGeough y Smith 2011: 266), RS 21.184A (McGeough y Smith 2011: 426-427) cuentan, además, con tejidos ya trabajados. Además, los textos RS 15.171A (McGeough y Smith 2011: 86-87), RS 15.115 (McGeough y Smith 2011: 130-133) y RS 15.082 (McGeough y Smith 2011: 125-126), no solo recoge tejidos de lana y/o lino ya confeccionados, sino que algunos aparecen ya tintados.

${ }^{90}$ RS 15.046 (McGeough y Smith 2011: 114-115)

${ }^{91}$ En el texto RS 19.056 (McGeough y Smith 2011: 348-349) se aprecia cómo, junto a una cierta cantidad de cobre, se recogen cantidades de pwt (Rubia tinctorum) y alumbre. Por su parte, el texto RS 16.005 (McGeough y Smith 2011: 383) recoge ciertas cantidades de telas confeccionadas y lino en bruto junto a cantidades de piedra de alumbre. ${ }_{92}$ McGeough 2007: 211. En el texto RS 18.024 (McGeough y Smith 2011: 225-227) podemos ver como se intercambian diferentes materiales, de entre ellos lana tintada por plata. En otros documentos como RS 11.855 (McGeough y Smith 2011: 448), RS 15.035 (McGeough y Smith 2011: 109), RS 15.053 (McGeough y Smith 2011: 117) aparecen una serie de tejidos con un valor en siclos de plata asociado que pueden constituir recibos de venta. Por su parte, también han aparecido en casas privadas documentos como RS 20.130 (Ug. V: 132-133) y RS 20.151 (Ug. V: 138-139) que indican transacciones relacionadas con tejidos entre altas instancias políticas. ${ }^{93}$ Es posible que estos comerciantes particulares estuvieran en una situación semiautónoma, permitiendo así que pudieran realizar sus negocios también en la esfera privada (McGeough 2015: 87-88), es decir, si bien actuaban con un alto grado de independencia respecto al poder palacial, siempre aparecen asociados a él (McGeough 2015: 91). En cualquier caso, estos personajes que aparecen dirigiendo operaciones comerciales a larga distancia acumularon riqueza y poder gracias a estas transacciones llegando incluso, con su experiencia, a ser los gestores de importantes relaciones diplomáticas, tal y como se desprende de la documentación diplomática encontrada en diferentes casas privadas.

${ }^{94}$ RS 12.033 (PRU III: 14-15), RS 15.062 (McGeough y Smith 2011: 118-120), RS 19.050 (PRU VI: 15-17), RS 18.089 (PRU VI: 17-18), RS 22.006 (PRU VI: 18), RS 18.024 (McGeough y Smith 2011: 225-227) y RS 18.028 (McGeough y Smith 2011: 231-233).

${ }^{95}$ Routledge y McGeough 2009: 27.
} 
Por su parte, es en casas particulares en donde se ha encontrado la gran mayoría de los documentos que, tanto relacionados con intercambios entre altas instancias políticas como estrictamente comerciales privados, hacen referencia a la venta y distribución de tejidos teñidos. Todo lo contrario a lo que se puede apreciar en lo relativo a la posesión y cuidado de cabezas de ovino, puesto que la contabilización que se ha hecho de este ganado por familia no supera las sesenta cabezas de media, algo verdaderamente minúsculo para poder decir que una economía doméstica podía basar su riqueza en el comercio de la lana ${ }^{96}$; además, apenas encontramos listas en las que se contabilicen cabezas de ganado ovino en los archivos encontrados en ámbito doméstico ${ }^{97}$. Sin embargo, contamos con textos administrativos procedentes de este mismo ámbito en los que igualmente se registran cantidades de tejidos ${ }^{98}$, así como su distribución entre individuos y/o colectivos ${ }^{99}$, además de listas de pastores ${ }^{100}$, las cuales señalan una especial vinculación entre los comerciantes privados, la producción lanar y la economía palacial y que apunta a una relación más allá de la del simple productor-intermediario eventual ${ }^{101}$.

Pese a que Ugarit contaba con producción propia de lana, podemos ver en ciertos textos que también se importa lana desde otros lugares como Ašdod ${ }^{102}$, Aškalon ${ }^{103}$ o Egipto ${ }^{104}$, además de las telas tirias mencionadas en textos del palacio real ${ }^{105} \mathrm{y}$ en documentos privados ${ }^{106}$. Del mismo modo, contamos con recibos de compras de lotes de lana ${ }^{107}$ que podrían estar relacionados con estas importaciones. Es posible que esta importación de un material como la lana, de la cual Ugarit no carecía, se deba a un intento por parte de los comerciantes particulares de no depender exclusivamente de la lana procedente de las haciendas palaciales. No obstante, el hecho de que igualmente el palacio requiera de la importación de lana nos hace pensar en una necesidad de abastecimiento puntual, bien por un descenso en la producción interna, bien por un aumento de la demanda externa.

En lo que respecta al comercio privado de lana y tejidos, varios de ellos teñidos, están documentados en diferentes textos junto al tráfico privado de piedra de alumbre ${ }^{108}$. Si nos concentramos en aquellos textos que mencionan el intercambio de tejidos teñidos ${ }^{109}$, se aprecia que la mayoría hacen referencia al comercio entre mercaderes emariotas, ugaritas y tirios. Junto a esto, la gran mayoría de estos documentos proceden de un solo archivo encontrado en ámbito doméstico, la Casa de Urtenu (fig. 1), edificio en donde, además de contener un importante archivo diplomático y una extraordinaria biblioteca de obras clásicas babilónicas ${ }^{110}$,

\footnotetext{
${ }^{96}$ Matoïan y Vita 2014: 315.

${ }^{97}$ RS 22.407 (McGeough y Smith 2011: 541), RS 34.163 (RSO VII: 83-84), RS 86.2247 (RSO XIV: 358-359) y RS 94.2515 (RSO XXIII: 139-140).

${ }^{98}$ RS 17.328 (Ug. V: 21) y RS 94.2197 (Malbran-Labat 2008: 22).

${ }^{99}$ RS 21.056 (McGeough y Smith 2011: 463) y RS 34.180,10 (RSO VII: 166-167).

${ }^{100}$ RS 24.301 (McGeough y Smith 2011: 453).

${ }^{101}$ En el documento RS 94.2412 (RSO XXIII: 121-123) se señala además la participación del rey de Ugarit como posible socio de mercaderes particulares al solicitarse que aporte sus barcos en el transporte de mercancías.

${ }^{102}$ RS 23.028 (McGeough y Smith 2011: 542-543).

${ }^{103}$ RS 94.2392+2400 (RSO XVIII: 90-95).

${ }^{104}$ RS 23.028 (McGeough y Smith 2011: 542-543) y RS 94.2002+2003 (RSO XXIII: 81-86).

${ }^{105}$ RS 15.004 (McGeough y Smith 2011: 98-99).

${ }^{106}$ RS 34.167+175 (RSO VII: 57-61) y 94.2485 (RSO XXIII: 126-128).

${ }^{107}$ RS 17.465 (Ug. V: 20-21).

${ }^{108}$ RS 34.133 (RSO VII: 76-78), RS 34.134 (RSO VII: 68-70), RS 34.141 (RSO VII: 70-71), RS 34.167+175 (RSO VII: 57-61), RS 34.173 (RSO VII: 72-73), RS 86.2236 (RSO XIV: 258-259), RS 88.2159 (RSO XIV: 379-384), RS 94.2419 (RSO XXIII: 148-149), RS 94.2485 (RSO XXIII: 126-128); RS 94.2500 (RSO XXIII: 130-131), RS 94.2589 (RSO XXIII: 162-163) y RS 94.2603 (RSO XVIII: 126-129).

${ }^{109}$ RS 34.133 (RSO VII: 76-78), RS 34.134 (RSO VII: 68-70), RS 34.141 (RSO VII: 70-71), RS 34.167+175 (RSO VII: 57-61), RS 34.173 (RSO VII: 72-73) y RS 94.2485 (RSO XXIII: 126-128).

${ }^{110}$ Bordreuil y Malbran-Labat 1995: 446.
} 
la literatura científica sitúa el centro de operaciones de un importante consorcio comercial que ponía en relación a mercaderes de la propia Ugarit con otros de Emar y Tiro ${ }^{111}$ (fig. 3). A pesar de que los estudios relacionados con la organización y objetivos de esta agrupación mercantil observaron que el producto principal que circulaba a través de ella era el aceite, recientemente se ha sugerido que además se interesaron por el comercio de la lana teñida ${ }^{112}$.

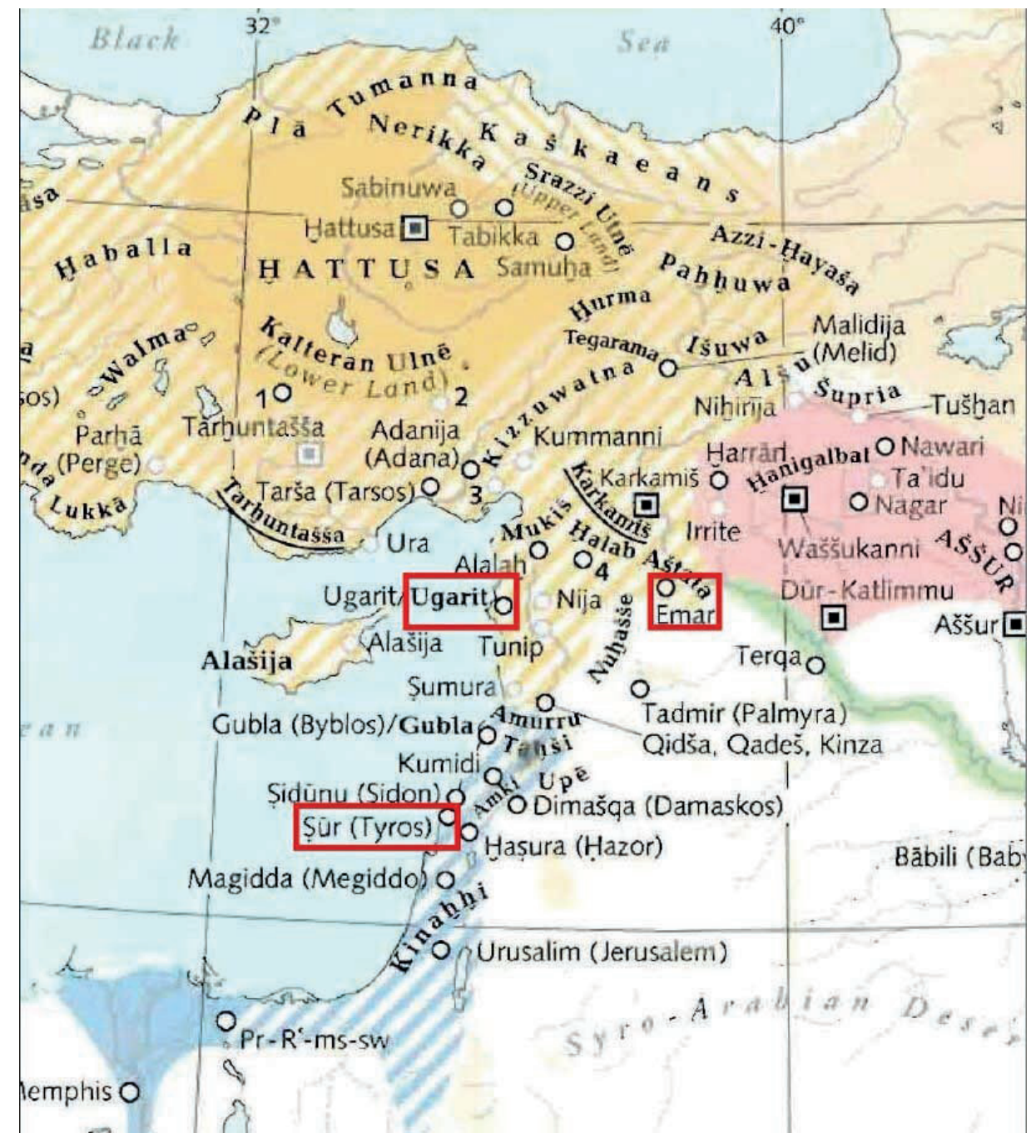

Fig. 3. Mapa político del Próximo Oriente antiguo durante el s. XIII a.C. (Wittke, Olshausen y Szydlak 2012: 15) con los tres centros urbanos implicados en la denominada firme: Ugarit, Emar y Tiro.

\footnotetext{
${ }^{111}$ Desde que empezaron a publicarse los textos encontrados en la Casa de Urtenu, se advirtió de la presencia de este grupo especial de cartas privadas de contenido comercial. D. Arnaud, (1991: 65-78) llega a reconocer hasta siete cartas que se corresponden con esta organización comercial: RS [varia 26], RS 34.134, RS 34.141, RS 34.173, RS 34.164, RS 34.153, RS 34.133. Por su parte, en la última publicación referente a los textos hallados en la Casa de Urtenu, S. Lackenbacher y F. Malbran-Labat (2016: 115-131) han individualizado ocho cartas comerciales privadas que se corresponderían con los negocios de esta firme: RS 94.2417, RS 94.2285+2286, RS 94.2412, RS 94.2416+2418, RS 94.2485, RS 94.2550, RS 94.2957, RS 94.2500.

${ }^{112}$ RSO XXIII: 117. La relación entre la actividad tintorera y las almazaras está incluso atestiguada a nivel arqueológico, situándose los centros de producción de textil muy cercanos a aquellos otros de producción de aceite, como el denominado Centro de la Ciudad (Callot 1987: 197-212) o la denominada Casa de las Tablillas Literarias (Roche-Hawley 2013: 425).
} 
Esta organización comercial internacional que reunía a mercaderes de esas tres ciudades señala el especial desarrollo que adquirió el comercio ugarita durante los últimos siglos del Bronce Final. Se trata de la extensión del comercio del que fuera el principal emporio del Mediterráneo oriental hacia sus dos principales mercados. Por un lado, encontró en Tiro el punto de apoyo necesario para asegurarse el acceso a los demás centros comerciales del mediterráneo oriental como los reinos de Siyannu-Ušnatu ${ }^{113}$, Beirut ${ }^{114}$, Biblos ${ }^{115}$, Sidón ${ }^{116}$ y la propia Tiro ${ }^{117} \mathrm{y}$, en última instancia, al mercado egipcio ${ }^{118}$. Por otro lado, la ciudad de Emar, situada en la rivera del Éufrates, permitía conectar Ugarit, a través del paso de Bdama, con las rutas que atravesaban la yazirah desde Asiria ${ }^{119}$ y las que remontaban el propio Éufrates desde Mesopotamia ${ }^{120}$.

\footnotetext{
${ }_{113}$ RS 20.017 (Ug. V: 128-129), RS 20.021 (Ug. V: 126-128), RS 20.219 (Ug. V: 129-131), RS 21.183 (Ug. V: 124-126), RS 22.419 (Roche-Hawley 2013: 441), RS 34.153 (RSO VII: 75-76), RS 34.158 (RSO VII: 44-46), RS 94.2445 (RSO XXIII: 90-91), RS 94.2484 (RSO XXIII: 93-95), RS 94.2521 (RSO XXIII: 183-184), RS 94.2591 (RSO XXIII: 91-93) y RS 94.2594 (RSO XXIII: 200-201).

${ }^{114}$ RS 11.730 (PRU III: 12-13), RS 34.137 (RSO VII: 79-80), RS 86.2212+2214A (RSO XIV: 264-265), RS 92.2021 (RSO XIV: 265-266), RS 94.2167 (RSO XXIII: 104-105), RS 94.2187 (RSO XXIII: 102-103), RS 94.2478 (RSO XXIII: 138-139) y RIH 81/04 (Bordreuil, Pardee y Roche-Hawley 2019: 287-289).

${ }^{115}$ RS 18.025 (McGeough y Smith 2011: 227-229), RS 34.145 (RSO VII: 32-34), RS 94.2182 (RSO XXIII: 99101) y RS 94.2598 (RSO XXIII: 101-102).

${ }^{116}$ RS 11.723 (PRU III: 9), RS 34.147 (RSO VII: 23-25), RS 34.149 (RSO VII: 80-81), RS 34.153 (RSO VII: 75-76), RS 86.2208 (RSO XIV: 273-275), RS 86.2221+2225+2226+2240 (RSO XIV: 267-272), RS 86.2234 (RSO XIV: 277), RS 94.2369 (RSO XXIII: 105-106), RS 94.2394 (RSO XXIII: 108), RS 94.2396 (RSO XXIII: 106-107), RS 94.2403 (RSO XXIII: 108-109) y RS 94.2438+2444 (RSO XXIII: 110-111).

${ }^{117}$ RS 18.031 (PRU V: 81-83), RS 34.167+175 (RSO VII: 57-61), RS 86.2211 (RSO XIV: 277-278), RS 94.2174 (RSO XXIII: 112-113), RS 94.2416+2418 (RSO XXIII: 123-126), RS 94.2485 (RSO XXIII: 126-128), RS 94.2595 (RSO XXIII: 189-190) y RS 94.2601 (RSO XXIII: 190-191).

${ }^{118}$ Los contactos con Egipto están demostrados desde el III milenio a.C. por pruebas arqueológicas (Matoïan, 2015). Respecto a los textos: RS 16.341 (McGeough y Smith 2011: 395), RS 18.042 (McGeough y Smith 2011: 239-240), RS 19.106 (McGeough y Smith 2011: 424-425), RS 20.021 (Ug. V: 126-128), RS 20.033 (Ug. V: 69-79), RS 20.182A+B (Ug. V: 111-114), RS 20.438 (Ug. V: 133-134), RS 23.028 (McGeough y Smith 2011: 542-543), RS 34.158 (RSO VII: 44-46), RS 34.173 (RSO VII: 72-73), RS 86.2230 (RSO XIV: 278-279), RS 88.2158 (RSO XIV: 239-247), RS 94.2002+2003 (RSO XXIII: 81-86), RS 94.2176 (RSO XXIII: 86-87), RS 94.2485 (RSO XXIII: 126-128) y RS 94.2597 (RSO XXIII: 96-98).

${ }^{119}$ Los contactos con Asiria se aprecian en RS 20.150 (Ug. V: 149-151), RS 23.025 (Arnaud 2003: 7-12), RS 34.165 (RSO VII: 90-100), RS 94.2369 (RSO XXIII: 105-106), RS 94.2446 (RSO XXIII: 180-181), RS 94.2474 (RSO XXIII: 155-158) y RS 94.2481+2576 (RSO XXIII: 181-182). Posiblemente, contemos con más cartas enviadas desde Asiria halladas en el palacio real como es el caso del documento RS 18.054A (PRU IV: 228-229) la cual sería una carta enviada por Tukulti-Ninurta I al rey de Ugarit (Llop Raduà 2015: 255) en los mismos términos de hermandad que en la carta RS 34.165. A éstas dos podríamos añadir la carta RS 18.268 (PRU IV: 229). Por otro lado, B. I. Faist (2001: 70) considera que entre los receptores de raciones de vino presentes en el texto RS 16.341 (McGeough y Smith 2011: 395-396) está el nombre de un asirio. Junto a estos datos contamos con la presencia de dos escribas asirios asentados en Ugarit, uno de ellos documentado en la denominada Casa de las Tablillas Literarias (Cohen 2017: 281) y el otro en la denominada Casa de Yabninu (van Soldt 2001: 430).

${ }^{120}$ Los contactos con Babilonia se pueden apreciar en los documentos RS 23.025 (Arnaud 2003: 7-12), RS 34.142 (RSO VII: 101-104), RS 34.152 (RSO VII: 84-86), RS 34.163 (RSO VII: 83-84), RS 34.169 (RSO VII: 17-18), RS 94.2292 (RSO XXIII: 167-168), RS 94.2369 (RSO XXIII: 105-106), RS 94.2446 (RSO XXIII: 180181), RS 94.2474 (RSO XXIII: 155-158) y RS 94.5026+5027 (RSO XXIII: 78-79). Por otro lado, la presencia de comerciantes babilonios en Ugarit está atestiguada textualmente por la carta que Hattušili III le hace llegar a su homólogo babilonio y en la que cita una queja que este último debió escribir en una carta previa. Aquí, el rey casita se queja de que sus "mercaderes están siendo asesinados en el país de Amurru, en el país de Ugarit y en el país de [...]..." (Beckman 1996: 136). Igualmente, ciertos rasgos paleográficos procedentes de textos eruditos encontrados en la denominada Casa del Sacerdote Hurrita indican la presencia de escribas babilonios en Ugarit (Van Soldt 2012: 173-177).
} 
En relación a esta última ruta, encontramos que en textos procedentes de Emar también se aprecia un interés por parte de comerciantes emariotas por el comercio de las telas, como se puede ver en los textos Msk $7234^{121}$ y Msk $73280^{122}$. Igualmente podemos ver este comercio en algunas cartas ${ }^{123}$ procedentes del denominado Templo $\mathrm{M}_{1}$ de Emar. Por su parte, las referencias en textos procedentes de archivos mesopotámicos y asirios a telas teñidas de los colores recurrentes que apreciamos en el comercio ugarita del tinte hacen pensar que, tal vez, gran parte de aquellas procedieran de este mercado ${ }^{124}$. Así pues, contamos con textos procedentes de Dur-Kurigalzu ${ }^{125}, \mathrm{Ur}^{126}$, Nippur ${ }^{127}$ y Aššur ${ }^{128}$ en donde encontramos referenciadas prendas de lana teñida de azul, púrpura, rojo y verde.

Sin embargo, otras pruebas llevan a plantear la posibilidad de que tanto Mesopotamia como Asiria contaran con una producción propia de tinte. Por un lado, Mesopotamia debió abastecerse de fuentes de cobalto diferentes a las egipcias, tal y como parecen demostrar los hallazgos de vidrio azul encontrados en $\operatorname{Nippur}^{129}$ y Dur Kurigalzu ${ }^{130}$; posiblemente procedentes de yacimientos de la región de Irán que sabemos se están explotando desde comienzos del II milenio a.C. ${ }^{131}$ Por otro lado, recientes estudios sobre un conjunto de restos de conchas halladas en Khor Île-Sud (Qatar) revelan la presencia de múrices en el Golfo Pérsico ${ }^{132}$ que pudieron abastecer de púrpura a las factorías tintoreras de Mesopotamia durante este periodo ${ }^{133}$. En este yacimiento aparecieron una serie de estructuras excavadas en el suelo de entre 20 y $75 \mathrm{~cm}$ de profundidad y entre $2 \times 2 \mathrm{~m}$ y $6,5 \times 2 \mathrm{~m}$ de extensión ${ }^{134}$ que recuerdan a las piletas supuestamente utilizadas para el teñido de tejidos que identificó O. Callot ${ }^{135}$ en Ugarit. De hecho, los restos hallados han sido datados en el s. XIII a.C. ${ }^{136}$

En lo que respecta a Asiria, también contamos con pruebas de una posible producción propia de tinte. Tal es el caso del texto A. 305 en el que se entrega a un individuo de nombre Šamaš-Amranni un lote de lana para ser tintada de púrpura, así como también una cantidad de 14 minas de Rubia tinctorum ${ }^{137}$. Otro documento recoge cantidades de lana tintada, alumbre

\footnotetext{
${ }^{121}$ En este documento aparece además un nombre que ya conocemos por archivos ugaritas y que fue un importante socio comercial de Urtenu, Dagan-bēlu (Arnaud 1986: 32-33).

${ }^{122}$ Arnaud 1986: 35-36. En este texto se aprecia además la vinculación de mercaderes babilonios con el comercio de telas en esta ciudad. De hecho, Y. Cohen y I. Singer (2006: 131) sitúan la presencia de un kārum babilónico en la Casa 5 del sector A de Emar, en cuyos documentos se han encontrado varios nombres de tradición babilónica, algunos de ellos relacionados directamente con Ugarit a través del documento RS 34.152 (RSO VII: 84-86).

${ }^{123}$ Msk 7475 (Arnaud 1986: 255) y Msk 7442 (Arnaud 1986: 256-257).

124 Thavapalan 2016: 179-180.

${ }^{125}$ IM 50023 (Gurney 1949: 137).

${ }^{126}$ IM 85528 (Gurney 1983: 149-150), IM 85530 (Gurney 1983: 153-154).

127 UM 29-16-550 (Sassmannhausen 2001: 406), N 2644 (Sassmannhausen 2001: 408) y UM 29-13-208 (Sassmannhausen 2001: 406).

128 VAT 18024, Ass. 3369, Ass. 3533 A 752, Ass. 13058 y VAT 15569 (Pedersén 1985: 75-76). Destacan especialmente los textos procedentes del archivo de Babu-aha-iddina: VAT 8015, VAT 8011, VAT 8231, VAT 8033, VAT 8028, VAT 8030, VAT 8024, VAT 8009, VAT 8861, VAT 8865, VAT 8236, VAT 8985, VAT 8993, VAT 9040 y John Rylands Library P.28 (Pedersén 1985: 110).

${ }^{129}$ Clayden 2011: 101.

${ }^{130}$ Moorey 1999: 197-198.

${ }^{131}$ Caubet et al. 2007: 22.

132 Edens 1999: 83.

133 Thavapalan 2016: 180.

${ }^{134}$ Edens 1999: 72.

${ }^{135}$ Callot 1994: 190.

${ }^{136}$ Edens 1999: 82. Este dato se suma al archivo casita encontrado en Qal'at al-Bahrein (André-Salvini y Lombard 1997: 167-168) y a la cerámica igualmente casita procedentes de Tell Abraq y que demuestran la especial expansión que la economía casita tuvo en este periodo en el Golfo Pérsico (Potts 1993: 123-124).

${ }^{137}$ Postgate 2013: 157.
} 
y Rubia tinctorum ${ }^{138}$ y los textos VAT 8030 y VAT 8839 procedentes del archivo de Babuaha-iddina recogen cantidades de alumbre ${ }^{139}$.

\section{Conclusiones}

En conclusión, la importancia que adquirió la industria del tinte en Ugarit se aprecia tanto en su producción como en su distribución y comercialización. Por un lado, destacan los términos específicos para cada tipo de tinte; por otro, pese al silencio de las fuentes textuales, los restos arqueológicos encontrados tanto en Ugarit como en otros lugares del Próximo Oriente antiguo han demostrado los materiales, algunos incluso procedentes del mercado internacional, y los complejos procesos artesanales que cada tipo de tinte requería. Ambos tipos de datos señalan la extraordinaria especialización que adquirió esta industria. Igualmente, aunque los textos no describen los lugares en donde debieron llevarse a cabo los procesos de teñido, ciertas estructuras han revelado posibles ubicaciones de dichos talleres, tanto dentro de la ciudad como en las zonas portuarias.

Sin embargo, lo que sí mencionan los textos es la gran fama que adquirieron los tintes ugaritas, siendo objeto de tributo exigido por parte de los soberanos hititas a los que Ugarit estuvo sometida durante gran parte del Bronce Final; así como producto altamente distribuido en forma de regalos diplomáticos con reinos vecinos y potencias extranjeras. Del mismo modo, los textos describen las complejas relaciones económicas que implicó su administración y venta en el mercado internacional, relaciones que van desde la producción y venta directa desde las altas instancias palaciales a la organización empresarial internacional por parte de mercaderes particulares, pasando por la relación productor-intermediario entre el propio palacio real y dichos mercaderes.

Así pues, gracias a la combinación de datos arqueológicos y textuales podemos reconstruir todo el proceso productivo que implicó el tinte en Ugarit, desde su fabricación hasta su distribución en los circuitos internacionales de la época. No obstante, aún se requieren estudios, tanto filológicos como arqueológicos, que permitan dilucidar y normalizar la compleja terminología de los distintos colores que mencionan los textos, así como identificar los talleres donde el teñido se llevaba a cabo y su organización.

\section{Bibliografía}

André-Salvini, B. y Lombard, P., 1997, "La découverte épigraphique de 1995 à Qal'at alBahrein: un jalon pour la chronologie de la phase Dilmoun Moyen dans le Golfe árabe", PSAS 27, pp. 165-170.

Arnaud, D., 1986, Recherches au pays d'Aštata. Textes sumériens et accadiens (Vol. 3), Paris.

Arnaud, D., 2003, "Prolégomènes à la rédaction d'une histoire d'Ougarit III. Ougarit et TukultiNinurta", SMEA 45, pp. 7-20.

Astour, M. C., 1995, "La topographie du royaume d'Ougarit", in M. Yon, M. Sznycer, P. Bordreuil (eds.), Le Pays d'Ougarit autour 1200 AV. J.-C. Histoire et Archeologie. Actes du Colloque International Paris, 28 juin - ler julliet 1993 (RSO XI), Paris, pp. 55-72.

de Ausejo, S. (trad.), 1975, La Biblia, Barcelona.

Beckman, G., 1996, Hittite Diplomatic Texts, Atlanta.

Bordreuil, P. (dir.), 1991, Une bibliothèque au sud de la ville (RSO VII), Paris.

\footnotetext{
${ }^{138}$ MARV 3.8 (Postgate 2013: 157).

${ }^{139}$ Pedersén 1985: 110; Postgate 2013: 218.
} 
Bordreuil, P. y Malbran-Labat, F., 1995, "Les archives de la maison d'Ourtenou”, CRAIBL 139 (2), pp. 443-451.

Bordreuil, P., Pardee, D. y Hawley, R., 2012, Une Bibliothèque au sud de la ville III. Textes 1994-2002 en cunéiforme alphabétique de la Maison d'Ourtenu, (RSO XVIII), Lyon.

Bordreuil, P., Pardee, D. y Roche-Hawley, C., 2019, Ras Ibn Hani II. Les textes en écriture cuneiformes de l'âge du Bronze récent (fouilles 1977 à 2002), Beyrouth.

Bounni, E. A., Lagarce, E. y Lagarce, J., 1998, Ras Ibn Hanni, I. Le Palais Nord du Bronze Récent. Fouilles 1979-1995, Synthèse Préliminaire, Beyrouth.

Brilli, A., 2018, El Viaje a Oriente, Madrid.

Bryce, T., 2001, El reino de los hititas, Madrid.

Callot, O., 1987, "Les huiliers du Bronze Récent à Ugarit", in M. Yon, (ed.), Le Centre de la Ville, 38e-44e campagnes (1978-1984) (RSO III), Paris, pp. 197-212.

Callot, O., 1994, La tranchée "Ville Sud". Études d'architecture domestique (RSO X), Paris.

Caubet, A. et al, 2007, Faïence et matières vitreuses de l'Orient ancien. Étude physico-chimique et catalogue des oeuvres du département des Antiquités orientales, Paris.

del Cerro Linares, C., 2011, “Azul para los dioses. De Oriente a Occidente: La búsqueda del lapislázuli durante el III milenio a.C.”, Isimu 13, pp. 71-103.

Clayden, T., 2011, “Glass Axes of the Kassite Period from Nippur”, ZOrA 4, pp. 92-135.

Cohen, R., 1992, “On Diplomacy in the Ancient Near East: the Amarna Letters", Diplomacy \& Statecraft 7(2), pp. 245-270.

Cohen, Y., 2017, "An Assyrian Teacher at Ugarit? A New Reading of the Colophon of Šima Milka (Hear the Advice) from the Maison aux tablettes", BiOr 64, pp. 274-283.

Cohen, Y. y Singer, I., 2006, “A Late Synchronism between Ugarit and Emar”, in Y. Amit et al. (eds.), Essays on Ancient Israel in its Near Eastern Context. A Tribute to Nadav Na'aman, Winona Lake, pp. 123-139.

Dardallion, E., 2012, "Le plomb dans les productions métalliques d'Ougarit” en V. Matoïan, M. Al-Maqdissi, Y. Calvet (eds.), Études Ougaritiques II (RSO XX), Leuven, pp. 221-240.

Edens, C., 1999, "Khor Ile-Sud, Qatar: The Archaeology of Late Bronze Age Purple-Dye Production in the Arabian Gulf", Iraq 61, pp. 71-88.

Estrabón, Geografía. Libros XV-XVII (trad. de 2015 de J. L. García-Alonso, M. P. de Hoz García-Bellido y S. Torallas Tovar), Madrid.

Faist, B. I., 2001, Der Fernhandel des assyrischen Reiches zwichen dem 14. und 11 Jh. v. Chr, Münster.

Fernández Uriel, P., 2010, Púrpura, del mercado al poder, Madrid.

Finkel, I., Granger-Taylor, H. y Cardon, D., 1999, "Un fragment de tablette inscrite en cunéiforme" in D. Cardon (ed.), Teintures precieuses de la Mediterranée: pourpre, kermes, pastel, Carcassonne, pp. 64-65.

Galliano, G. y Calvet, Y. (eds.), 2004, Le royaume d'Ougarit: aux origines de l'alphabet, Paris.

Gurney, O. R., 1949, “Texts from Dur-Kurigalzu”, Iraq 11, pp. 131-142.

Gurney, O. R., 1983, The Middle Babylonian Legal and Economic Texts from Ur, Oxford. 
James, M. A. et al., 2009, "High prestige Royal Purple dyed textiles from the Bronze Age royal tomb at Qatna, Syria", Antiquity 83, pp. 1109-1118.

Kiely, T., 2019, "Los fenicios", in A. Fletcher (coor.), Lujo. De los asirios a Alejandro Magno, Barcelona, pp. 81-89.

Lackenbacher, S., 2002, Textes Akkadiens d'Ugarit. Textes provenant des 25 premières campagnes, Paris.

Lackenbacher, S. y Malbran-Labat, F., 2016, Lettres en Akkadien de la «Maison d'Urtenu». Fouilles de 1994 (RSO XXIII), Paris.

Leight, B., 2019, “Ostentación personal: lujo y joyas", in A. Fletcher (coor.), Lujo. De los asirios a Alejandro Magno, Barcelona, pp. 141-151.

Liverani, M., 2003, Relaciones internacionales en el Próximo Oriente antiguo, 1600-1100 a.C., Barcelona.

Llop Raduà, J., 2015, "Foreign Kings in the Middle Assyrian Archival Documentation", in B. S. Düring (ed.), Understanding Hegemonic Practices of the Early Assyrian Empire. Essays Dedicated to Frans Wiggerman, Leiden, pp. 243-273.

Malbran-Labat, F., 2008, "Catalogue raisonné des textes akkadiens de la 'Maison d'Urtēnu"” in C. Roche (ed.), D'Ougarit a Jerusalem: recueil d'etudes epigraphiques et archeologiques offert a Pierre Bordreuil, Paris, pp. 21-38.

Mallet, J. y Matoïan, V., 2001, 'Une maison au sud du 'temple aux rhytons' (fouille 19791990)", in M. Yon, D. Arnaud (eds.), Études ougaritiques I, Travaux 1985-1995 (RSO XIV), Paris, pp. 83-190.

Márquez Rowe, I., 2002, "The King's Men in Ugarit and Society in Late Bronze Age Syria", JESHO 45(1), pp. 1-19.

Matoïan, V., 2008, “Ougarit blues”, in C. Roche (ed.), D’Ougarit à Jérusalem. Recueil d'études épigraphiques et archéologiques offerts a Pierre Bourdreil, Lyon, pp. 81-96.

Matoïan, V., 2015, “Ugarit et l'Égypte: essai d'interpretation de la documentation archéologique et perpectives de la recherche", in B. Eder, R. Pruzsinsky (eds.), Policies of Exchange. Political Systems and Modes of Interaction in the Aegean and the Near East in the 2nd millennium B.C.E. Proceedings of the International Symposium at the Universty of Freiburg Institute for Archaeological Studies, 30th May - 2nd June 2012, Wien, pp. 35-84.

Matoïan, V. y Bouquillon, A., 2003, "Vitreous Materials in Ugarit: New Data", in T. Potts, M. Roaf, D. Stein (eds.), Culture through objects: Near Eastern Studies in honour of P.R.S. Moorey, Oxford, pp. 333-346.

Matoïan, V. y Vita, J. P., 2009, "Les textiles à Ougarit. Perspectives de la recherche", UF 41, pp. 469-504.

Matoïan, V. y Vita, J. P., 2014, "Wool Production and Economy at Ugarit", in C. Breniquet, C. Michel (eds.), Wool Economy in the Ancient Near East and the Aegean. From the Beginnings of Sheep Husbandry to Institutional Textile Industry, Oxford, pp. 310-339.

Matoïan, V. et al., 2013, "Rapport préliminaire sur les activités de la mission archéologique syrofrançaise de Ras Shamra - Ougarit en 2009 et 2010 (69e et 70e campagnes)”, Syria 90, pp. 439-478.

McGeough, K., 2007, Exchange Relationships at Ugarit, Leuven. 
McGeough, K., 2015, “«What Is Not in My House you Must Give Me»: Agents of Exchange According to the Textual Evidence from Ugarit", in B. Eder, R. Pruzsinsky (eds.), Policies of Exchange. Political Systems and Modes of Interaction in the Aegean and the Near East in the 2nd millennium B.C.E. Proceedings of the International Symposium at the University of Freiburg Institute for Archaeological Studies, 30th May - 2nd June 2012, Wien, pp. 85-96

McGeough, K. y Smith, M. S., 2011, Ugaritic Economic Tablets. Texts translations and notes, Leuven.

Moorey, P. R. S., 1999, Ancient Mesopotamian Materials and Industries. The Archaeological Evidence, Oxford.

Nougayrol, J. et. al., 1968, Nouveaux textes accadiens, hourrites et ugaritiques des archives et bibliothèques privées d'Ugarit, commentaires des textes historiques (Ug. V), Paris.

Pedersén, O., 1985, Archives and Libraries in the City of Assur (vols. 1-2), Upsala.

Postgate, N., 2013, Bronze Age Bureaucracy. Writing and the Practice of Government in Assyria, Cambridge.

Potts, D., 1993, “Four seasons of excavation at Tell Abraq (1989-1993)” PSAS 23, pp. 117-126.

Rapp, G., 2009, Archaeomineralogy, Berlin.

Roche-Hawley, C., 2013, “Scribes, Houses and Neighbourhoods at Ugarit”, UF 44, pp. 413-444.

Routledge, B. y McGeough, K., 2009, "Just What Collapsed? A network perspective on 'palatial' and 'private' trade at Ugarit", in C. Bachhuber, R. Roberts (eds.), Forces of Transformation: The End of the Bronze Age in the Mediterranean, Oxford, pp. 22-29.

Saadé, G., 2011, Ougarit et son royaume. Des origines à sa destruction, Beyrouth.

Sassmannhausen, L., 2001, Beiträge zur Verwaltung und Gesellschaft Babyloniens in der Kassitenzeit, Mainz am Rhein.

Schaeffer, C. F. A., 1931, "Les fouilles de Minet el-Beida et de Ras-Shamra. Deuxième campagne (printemps 1930). Rapport sommaire”, Syria 12(1), pp. 1-14.

Schaeffer, C. F. A., 1951, "Une industrie d'Ougarit: la pourpre", Annales Archeologiques de Syrie 2, pp. 188-192.

Schaeffer, C. F. A. y Nougayrol, J. (eds.), 1956, Textes accadiens des archives sud (Archives internationales) (PRU IV), Paris.

Schaeffer, C. F. A. y Nougayrol, J. (eds.), 1970, Textes en cunéiformes babyloniens des archives $d u$ Grand Palais et du Palais Sud d'Ugarit (PRU VI), Paris.

Schaeffer, C. F. A. y Virolleaud, C. (eds.), 1965, Textes en cunéiformes alphabétiques des archives sud, sud-ouest et du petit palais, (PRU V), Paris.

Schaeffer, C. F. A. et al. (eds.), 1955, Textes accadiens et hourrites des archives est, ouest et centrales (PRU III), Paris.

Shortland, A. J., 2006, "Ancient Exploitation and Use of Cobalt Alums from the Western Oasis of Egypt”, Archaeometry, 48(1), pp. 153-168.

Sukenik, N. et al., 2017, "Early evidence (late 2nd millennium BCE) of plant-based dyeing of textiles from Timna, Israel”, PLOS ONE 12(6), pp. 1-24. doi: 10.1371/journal.pone.0179014

Thavapalan, S., 2016, "Purple Fabrics and Garments in Akkadian Documents", JANEH 3(2), pp. $163-190$. 
Thavapalan, S., 2019, "Stones from the Mountain, Stones from the Kiln: Colour in the Glass Texts from Ancient Mesopotamia", in S. Thavapalan, D. A. Warburton (eds.), The Value of Colour. Material and Economic Aspects in the Ancient World, Berlin, pp. 177-201.

Van de Mieroop, M., 2007, The Eastern Mediterranean in the Age of Ramesses II, Oxford.

Van Soldt, W. H., 1990, "Fabrics and Dyes at Ugarit", UF 22, pp. 321-357.

Van Soldt, W. H., 2001, "Nahish-shalmu, an Assyrian Scribe Working in the «Southern Palace» at Ugarit", in J. G. Dercksen et al. (ed.), Veenhof Anniversary Volume, Leuven, pp. 429-444.

Van Soldt, W. H., 2012, “The Palaeography of Two Ugaritic Archives”, in E. Devecchi (ed.), Palaeography and Scribal Practices in Syrio-Palestine and Anatolia in the Late Bronze Age, Leiden, 171-183.

Vita, J. P., 2010, "Textile Terminology in the Ugaritic Texts", in C. Michel, M. L. Nosch (eds.), Textile Terminologies in the Ancient Near East and Mediterranean from the third to the First Millennium, Oxford, pp. 323-337.

Vita, J. P., 2017, "Oil in Ugarit: its price, its use as means of payment and administrative procedures. Addendum: oil for wool”, UF 48, pp. 525-544.

Wittke, A. M., Oshlausen, E. y Szydlak, R., 2012, Historischer Atlas der antiken Welt, Stuttgart. Paris.

Yon, M. y Arnaud, D. (eds.), 2001, Études Ougaritiques I, Travaux 1985-1995 (RSO XIV),

Yon, M., Lombard, P. y Rensio, M., 1987, “L'organisation de l'hatitat : les maisons A, B et E”, in M. Yon (ed.), Le Centre de la Ville, 38e-44e campagnes (1978-1984) (RSO III), Paris, pp. 11-128.

Yon, M. et al., 1983, "Fouilles de Ras Shamra-Ougarit 1981-1983 (41e, 42e et 43e campagnes)", Syria 60(2), pp. 201-224.

Zaccagnini, C., 1973, Lo scambio dei doni nel Vicino Oriente durante i secoli XV-XIII, Roma.

Zaccagnini, C., 1990, "The forms of alliance and subjugation in the Near East", in L. Canfora, M. Liverani, C. Zaccagnini (eds.), I trattati nel mondo antico: forma ideologia e funcione, Roma, pp. 37-79.

Zaccagnini, C., 2000, "The Interdependance of the Great Powers", in R. Cohen, R. Westbrook (eds.), Amarna Diplomacy. The Beginning of International Relations, Baltimore, pp. 141-153. 